\title{
“Hasta la Revolución...y información!": análise histórica sobre o desenvolvimento dos campos em biblioteconomia e ciência da Informação em Cuba (1959-2008)
}

\author{
Roberto Lopes dos Santos Junior \\ bobblopes@hotmail.com \\ Doutorando em Ciência da Informação IBICT/ UFRJ
}

Resumo: Análise histórica, a partir de levantamento bibliográfico e revisão de literatura em fontes secundárias, apresentando o desenvolvimento da Ciência da Informação e biblioteconomia em Cuba, entre a revolução de 1959 até o final do governo de Fidel Castro, em 2008. O trabalho inicialmente fez breve análise sobre as origens e desenvolvimento do campo em biblioteconomia em Cuba até a década de 1950, e identificou como os campos em biblioteconomia e informação do país foram organizados nos primeiros anos após a revolução de 1959. Posteriormente, a pesquisa analisou os projetos e sistemas em informação realizados no país entre os anos 1970 e 1980, diretamente vinculados a programas similares realizados no bloco socialista, e, por fim, identificou as principais características das cenas em informação e biblioteconomia cubanas após a dissolução da URSS, em 1991. A pesquisa identificou que, apesar das limitações sofridas por essas disciplinas após o fim do campo comunista, as cenas cubanas em biblioteconomia e Ciência da informação possuíram consistência em sua estrutura e constituição.

Palavras-chave: Biblioteconomia em Cuba; Ciência da Informação em Cuba; Informação científica em Cuba.

Abstract: Historical analysis, based on literature review of secondary sources, identifying the development of the Information Science and Librarianship in Cuba, between the 1959 revolution until the end of Fidel Castro's Regime, in 2008. This work initially made a historical analysis about the origins of the Librarianship in Cuba until the 1950s, and how the information and library fields in Cuba are organized in the first years after the 1959 revolution. Later, the research discuss the information projects and systems produced in the country in the 1970s and 1980s, based on similar examples made by the socialist bloc, and how was the principal characteristics of the Information Science and Librarianship in Cuba after the dissolution of the USSR in 1991. This research found that, despite the problems suffered by theses fields after the dissolution of the communist bloc, the Librarianship and Information Science scenes in Cuba presents consistency in their structure and constitution.

Keywords: Librarianship in Cuba; Information Science in Cuba; Scientific information in Cuba. 


\section{INTRODUÇÃO}

As palavras Cuba e Fidel Castro, apesar de não possuírem o mesmo impacto de outrora, ainda podem, dependendo das circunstâncias, serem motivo de acaloradas discussões de pessoas com convicções políticas de direita ou esquerda.

Em parte, essa polêmica, mesmo defasada com a entrada do século XXI, e com o país caribenho atualmente lutando para sobreviver a uma duradoura crise econômica, pode ser justificada pelo impacto ideológico sofrido pela América Latina com a ascensão do governo de Fidel Castro ao poder em 1959. Em poucos anos, o país embarcaria em uma realidade marcada, por um lado, em amplas reformas políticas e sociais internas, e, de outro, na tentativa da exportação de sua "revolução" para outros países da América Latina e, em menor medida, na África, causando uma longa, e até hoje em vigor, hostilidade com o vizinho EUA, que, além de uma malfadada tentativa de invasão a Cuba em 1961, mantém por décadas um agressivo embargo econômico ao país.

Outro aspecto que também atraiu atenção internacional a Cuba foi a adesão do mesmo ao bloco comunista, sendo o único país socialista das Américas. Mesmo que essa adesão tenha sido tardia- somente no final dos anos 1960 Cuba entraria de forma efetiva na esfera soviética-, problemática - com a URSS, durante os anos 1980, mostrando interesse em se afastar de seu aliado caribenho-, e além do regime cubano ter assimilado defeitos e problemas advindos do sistema repressivo e centralizado soviético, até o inicio dos anos 1990, Cuba apresentou considerável desenvolvimento humano e estabilidade econômica, chamando a atenção de outros países do continente ${ }^{1}$.

Os campos em informação e biblioteconomia cubanos não ficaram imunes a esse período de mudanças no país. Os mesmos, apesar de possuírem uma estrutura relativamente desenvolvida antes da revolução, entrariam nos anos 1960 em um longo período de reorganização e em projetos, grande parte deles em conjunto com a União Soviética, visando expandir as bibliotecas e os serviços em informação no país, sendo que, após o fim da URSS, em 1991, esses campos entrariam em um novo período de reestruturação.

Foi constatado, a partir da análise em periódicos brasileiros, carência de bibliografias que discutem como o campo da Ciência da Informação se desenvolveu em Cuba, apesar de um crescente número de trabalhos cubanos recentes darem atenção a esses aspectos. A tentativa de suprir, mesmo que parcialmente, essa "lacuna", serviu de justificativa para o desenvolvimento desse trabalho.

\footnotetext{
${ }^{1}$ Para análises gerais sobre a realidade cubana após 1959, indicam-se, inicialmente, a leitura dos trabalhos de Ayerbe (2004), Gott (2006) e Reis Filho (2011). Para dados sobre o líder Fidel Castro, citam-se os trabalhos de Szulc (1986) e Furiati (2003), esse último com boas informações, apesar do caráter parcial e laudatório da obra.
} 
A presente pesquisa analisou o desenvolvimento da Ciência da Informação e Biblioteconomia em Cuba, entre a revolução de 1959 até o final do governo de Fidel Castro, em 2008. Esse artigo tem como objetivo apresentar informações sobre de que forma o único país comunista latino americano construiu e desenvolveu seu campo informacional e biblioteconômico, aparentemente destoando de outros países do continente.

A pesquisa, de caráter histórico, baseou-se no levantamento bibliográfico e revisão de literatura em fontes secundárias, focado em periódicos cubanos (em especial as revistas ACIMED e Ciencias de la Información), e, de forma complementar, em publicações brasileiras, norte-americanas e europeias. A partir desse levantamento, foram separados e analisados artigos que, de diferentes maneiras, realizaram estudos sobre o desenvolvimento dos campos em informação e biblioteconomia em Cuba, onde foram incluídos no trabalho dados históricos e de caráter qualitativo e quantitativo.

Inicialmente, foi feita breve análise sobre as origens e desenvolvimento do campo em biblioteconomia em Cuba até a década de 1950. Posteriormente, estudou como os campos em biblioteconomia e informação foram organizados nos primeiros anos após a revolução de 1959, onde são percebidas, por um lado, iniciativas de cunho regional e autônomas, mas também a influência cada vez mais crescente de órgãos soviéticos no cenário informacional cubano. Depois, foram discutidos os projetos e sistemas em informação realizados no país entre os anos 1970 e 1980, diretamente vinculados a programas similares realizados no bloco socialista, e, por fim, identificou as principais características das cenas em informação e biblioteconomia cubanas após a dissolução da URSS em 1991.

\section{BREVE HISTÓRICO SOBRE O CAMPO EM INFORMAÇÃO E BIBLIOTECAS NA CUBA PRÉ- REVOLUCIONÁRIA}

As origens dos serviços em documentação e biblioteconomia em Cuba datam dos primórdios do governo espanhol no país, durante os séculos XVI e XVII, onde a igreja católica (especificamente nas denominações franciscana, jesuíta e dominicana) seria praticamente a única instituição a publicar livros em terras cubanas, além de organizar esse material em acervos particulares pelo país (PÉREZ MATOS, 2005; 2007a; PÉREZ, HERRERA, 2006).

Os primeiros registros da existência de bibliotecas em Cuba datam de 1665, a partir do testamento do presbítero Nicolás Estebes Borges, que afirmou a existência de uma biblioteca particular com cerca de mil livros doados para a igreja de Havana, e de outras bibliotecas particulares ligadas à igreja católica cubana, porém sem apresentar maiores informações a 
respeito desses acervos (PÉREZ MATOS, 2005; 2007a; PUERTAS; RODRIGUEZ, 2005b; PÉREZ, HERRERA, 2006).

Durante o século XVIII, seriam criados arquivos e bibliotecas ligados diretamente ao governo espanhol ali instalado, em organismos como, por exemplo, a Sociedade Econômica de Amigos do País, oferecendo os primeiros sinais da consolidação de um campo de estudo e trabalho ligados às bibliotecas em Cuba (PUERTAS; RODRIGUEZ, 2005b; PÉREZ, HERRERA, 2006).

Em 1723, ofícios promulgados pela Espanha consolidaram a permissão para a impressão de livros em solo cubano, estimulando a produção, e posteriormente o armazenamento dessas publicações, mesmo que de forma bastante reduzida em um primeiro momento. Outras medidas consideradas importantes foram a constituição da Universidade de São Jerônimo de Havana, em 1728,- primeiro local de formação de profissionais em bibliotecas no país-, a consolidação de quatro locais de impressão de livros nos anos 1740, e o aparecimento de legislações que regulamentaram, de forma primitiva e diretamente ligada aos acervos particulares, as bibliotecas e os serviços de Documentação em Cuba (PÉREZ MATOS, 2005; 2007a; PÉREZ, HERRERA, 2006).

O século XIX seria marcado por um longo período de instabilidade no país, visualizadas em uma duradoura crise política interna e de algumas revoltas brutalmente reprimidas, consequência do declínio do império espanhol, consolidado na desastrosa guerra com os EUA em 1898, marcando o fim do domínio do país a Cuba.

O campo em informação e bibliotecas no país não ficaram imunes a esse período de crise, sendo que, apesar da atuação localizada de acadêmicos como José de la Luz Caballero (1800-1862), e do aparecimento de bibliotecas públicas isoladas nos anos 1840, a construção regular de bibliotecas públicas no país, além de reorganização dos acervos particulares e universitários, somente aconteceriam a partir de 1894, com a ocupação espanhola próxima de seu termino. (PÉREZ MATOS, FERNANDEZ MOLINA, 2010; SANTOS, HIDALGO, 2012).

Pérez Matos (2007a) afirma que, na década de 1890, seriam publicados cerca de 68 livros em solo cubano, diferente dos apenas dois títulos localizados pela autora nos anos 1810 .

As primeiras décadas do século $\mathrm{XX}$, com projetos oferecidos pelo governo cubano entre 1919 e 1927, mas especialmente após os anos 1930, testemunharam a consolidação acadêmica da biblioteconomia em Cuba. Em 1936, instituía-se a primeira disciplina ligada a biblioteconomia no país, e em 1947 criou-se o primeiro curso de biblioteconomia, ligado a faculdade de artes e literatura da Universidade de Havana. Também foram consolidados a construção e instalação de bibliotecas pelo país. Em 1951, 483 de bibliotecas, sendo 108 
públicas, estavam em atividade (GALÁN, 2009). Entre os anos 1940 e 1950 seriam realizados, de caráter esporádico e irregular, encontros nacionais unindo bibliotecários e os usuários das bibliotecas públicas cubanas (VIVERO et. al., 2007).

Apesar do clima sombrio existente nos últimos anos do regime do presidente Fulgencio Batista, entre 1952 e 1958, esse período viu florescer as bases para o desenvolvimento de um sistema de bibliotecas no país. Em 1952, fundava-se Associação Nacional de Profissionais em Bibliotecas, que durante a década de 1950 publicou o periódico Cuba Bibliotecológica, principal revista científica relacionada aos campos em biblioteca no país nessa época (VIVERO et. al., 2007).

Apesar de serem percebidas medidas de cunho autoritário do governo cubano, em que os cursos e projetos de pesquisa ligados à biblioteconomia sofreram censura, e aonde as bibliotecas públicas tiveram forte controle governamental na escolha do acervo a ser constituído, os anos 1950 seriam o período onde o país apresentou o maior número de publicações científicas, somente sendo superada durante a década de 1980 (SANTOS, PÉREZ MATOS, FERNANDEZ MOLINA, 2011).

O campo em biblioteconomia de Cuba manteve relações amigáveis, porém limitadas, com os cenários norte-americano, europeu e com países da América Latina (apesar de utilização do sistema Decimal de Dewey para classificar seus acervos, e da utilização das ideias de pesquisadores estadunidenses como, por exemplo, Jesse Shera, em alguns cursos de biblioteconomia no país) (SANTOS, PÉREZ MATOS, FERNANDEZ MOLINA, 2011).

\section{ESTRUTURAÇÃO E CONSOLIDAÇÃO: A CIÊNCIA DA INFORMAÇÃO E BIBLIOTECONOMIA CUBANA NOS PRIMEIROS ANOS PÓS-REVOLUÇÃO (1959-1970)}

Nos primeiros meses de 1959, o governo cubano recém-instaurado buscou estimular a continuação da produção de artigos e publicações relacionadas a bibliotecas e unidades de informação, além de algumas adaptações para a nova realidade política emergente no país.

Em relação às bibliotecas cubanas, as iniciativas realizadas pela bibliotecária Maria Teresa Freyre de Andrade (1896-1975) estimularam mudanças não somente no principal órgão biblioteconômico cubano, a Biblioteca Nacional Jose Martí, como em acervos ligados as instituições públicas e privadas, buscando ampliar tanto seu acervo como o leque de usuários a utilizarem esses organismos (VALDÉS, 2006). Andrade buscou também evitar que a área não sofresse com a confusa e instável realidade sofrida pelo campo em biblioteconomia no país, com o fim ou interrupção de acordos referentes à troca de material científico com os EUA e 
alguns países da Europa, e da fuga ou afastamento de bibliotecários na primeira metade dos anos 1960 (VALDÉS, 2006).

Em 1961, consolidou-se o surgimento da primeira geração de bibliotecários cubanos ligados ao governo de Fidel (destaque para María Villar Buceta, Vicentina Antuña, e Jorge Aguayo), alguns deles em atividade durante o regime de Batista. Influenciados pela campanha do fim do analfabetismo em Cuba promovido pelo governo nesse período, esses profissionais estimularam a criação da Rede Nacional de Bibliotecas e o Diretório Nacional de Bibliotecas Públicas, ligadas ao Conselho nacional de cultura cubano, e da consolidação de leis regulamentando o profissional em bibliotecas no país (VALDÉSA, 2006).

A partir dessas redes, departamentos como, por exemplo, os de Ciência e Técnica ou o Juvenil, tiveram importante papel em produzir bibliografias e material para estudantes cubanos e profissionais que buscavam guias ou outros tipos de publicações técnicas (PUERTAS, RODRIGUEZ, 2005a).

A partir dessas iniciativas, foram consolidados, a partir de 1962, novos cursos de formação para bibliotecários, e a realização, durante toda a década de 1960, de eventos reunindo a classe bibliotecária cubana, como, por exemplo, no primeiro fórum nacional de bibliotecários, realizado em 1964, e em campanhas nacionais de leitura, realizadas entre 196365 (VALDÉS, 2006).

A partir de 1964, foram efetuados, com a supervisão da Biblioteca Nacional Cubana, modificações e ajustes nos conteúdos programáticos dos cursos em biblioteconomia no país. Apesar de incentivos da utilização de autores soviéticos e da Europa Oriental, essas reformas, em um primeiro momento, mantiveram a utilização de autores norte-americanos e ocidentais, e do aproveitamento do método decimal por bibliotecários em Cuba (VALDÉS, 2006).

No final da década de 1960, gradativamente, visões e teorias soviéticas, além do método de classificação universal, seriam incorporadas em alguns cursos e bibliotecas do país. Porém, metodologias e abordagens teóricas produzidas nos EUA e Europa ocidental nunca seriam totalmente abandonadas em terras cubanas (VALDÉS, 2006; IZQUIERDO, 2004).

Entre 1961-63, visitas localizadas de profissionais ligados a UNESCO e do Instituto Estatal de Informação Científico e Técnica (VINITI)- principal organismo relacionado a informação científica na União Soviética-, ajudaram a solidificar as relações entre o (ainda primitivo) campo de estudo em informação cubano com o da URSS, sendo que os soviéticos ofereceriam dados e material necessário para a constituição dos primeiros organismos e programas de informação em Cuba. Em certo aspecto, algumas dessas medidas buscavam 
manter a estrutura existente na área no país durante os anos 1950, em que existiam congressos e cursos regulares, além de alta produção bibliográfica (IZQUIERDO, 2004).

Em 19 de abril de 1963, foi instituído o Instituto de Informação Científica e Tecnológica (IDICT), vinculado a Academia de Ciências Cubana, sendo uma consolidação prática de leis e regimentos que buscavam regulamentar e centralizar as atividades de informação no país, até aquele momento disperso em diferentes instituições de ensino. Inicialmente, o organismo teve três principais funções (IZQUIERDO, 2004):

- Criação de mecanismos metodológicos e organizacionais para elaboração, registro e divulgação da informação científica e tecnológica.

- Dedicar atenção para a formação de especialistas na atividade técnico informativa.

- Estabelecer a base para a criação de um sistema nacional de informação técnico científica em Cuba.

A bibliografia consultada apresenta controvérsia sobre qual a extensão da influência do VINITI na constituição do instituto em seus primeiros anos. Apesar de tentar manter certa independência em seu funcionamento e organização, percebeu-se que o IDICT possuiu, mesmo que de forma não totalmente clara, suporte e sugestões do instituto soviético, moldando sua estrutura e funções a organismos existentes no leste europeu e URSS.

Somente entre novembro e dezembro de 1965, quando o diretor do VINITI, Alexander Ivanovich Mikhailov, visitou o país, e foram assinados convênios de cooperação entre os dois institutos, que se transformariam num amplo programa de reestruturação do IDICT sob os moldes soviéticos, é que seria identificada como e em qual intensidade se deu a influência do VINITI no instituto (IZQUIERDO, 2004).

Em fevereiro de 1966 foi realizada a Primeira reunião em informação científica e técnica, organizada pelo IDICT, reunindo cerca de 38 instituições e organismos no país. Nessa reunião, seria proposta, pela primeira vez, a constituição de um sistema unificado em informação científica e técnica para Cuba. Contudo, apesar de características serem apresentadas e de algumas regulamentações sobre as bibliotecas cubanas e órgãos que lidavam com a informação científica serem desenvolvidas, muito do que foi apresentado nesse evento somente tomaria forma na década seguinte (IZQUIERDO, 2004).

Nesse período, o periódico Cuba Bibliotecológica, apesar de continuar em atividade, de forma irregular, seria substituído pelo Actualidades de la Documentación como principal periódico referente as áreas de informação e biblioteconomia em Cuba. Em atividade entre 1968 e 1973, a publicação seria renomeada Actualidades de la Información Científica y Técnica 
(1973-1990), e, desde 1991,em atividade como Ciencias de la Información (PÉREZ MATOS, FERNANDEZ MOLINA, 2010).

Em 1969, Cuba foi inserida na recém-criada Rede Internacional de Informação Científica (MSNTI), na qual a URSS tentava suprir os países sob sua influência de material científico publicado nos países ocidentais, além de tentar centralizar e padronizar os serviços em informação no bloco comunista (SANTOS JUNIOR, PINHEIRO, 2010; GALÁN, 2009).

Com essa inclusão, iniciava-se o que seria chamado de "fase de ouro" do campo em informação e bibliotecas no país. Mesmo que o preço a ser pago por essa "bonança" fosse uma adaptação acrítica dessas áreas aos moldes oferecidos pelos soviéticos.

\section{MOLDANDO UMA IDENTIDADE SOCIALISTA: A CIÊNCIA DA INFORMAÇÃO E BIBLIOTECONOMIA CUBANA DURANTE OS ANOS 1970 E 1980}

Durante os anos 1970, estabilizavam-se as políticas de expansão das bibliotecas públicas em Cuba, consolidando as iniciativas realizadas entre 1961-64. Segundo Puertas e Rodrigues (2005a), em 1975 funcionavam cerca de 121 bibliotecas públicas e 747 minibibliotecas- que trabalhavam em caráter voluntário -, sendo visualizado um aumento constante no número de bibliotecas em Cuba desde 1963. Em 1980, esse número chegaria a quase 200 bibliotecas públicas (169 delas municipais) em atividade (VALDÉS, 2006).

Segundo Santos e Hidalgo (2012), cerca de um milhão de volumes estavam disponíveis em universidades, instituições públicas e cursos, confirmando a expansão dos serviços bibliotecários cubanos em diferentes acervos do país. Grande parte desse material vinha do bloco socialista, e a partir da segunda metade dos anos 1970, Cuba participou de projetos em conjunto com países africanos em Angola, Moçambique e Etiópia, enviando material e profissionais para as bibliotecas desses países, projetos que teriam sucesso apenas limitado, e encerrados no final da década seguinte (SANTOS, HIDALGO, 2012).

Conforme citado anteriormente, seria na década de 1980 que a produção de livros, periódicos e artigos no país superou a produção obtida durante a década de 1950 (PERÉZ MATOS, 2007b). A partir de 1985, foram feitos trabalhos, organizados pela Biblioteca Nacional Cubana, no sentido de categorizar as bibliotecas do país, esforços esses malsucedidos, parcialmente explicados pela extinção de organismos como o Diretório Nacional de Bibliotecas, que acabaram sobrecarregando a Biblioteca Nacional Cubana e encerrando esses projetos em 1990 (VALDÉS, 2006).

Destacam-se também esforços dos bibliotecários Sidroc Ramos e Olinta Ariosa (19211999), que continuaram, nos anos 1970 e 1980, com os projetos e esforços realizados por 
Maria Teresa de Andrade na Biblioteca Nacional Cubana e em outros organismos (VALDÉS, 2006).

Entre 1980-89 foram realizados os Encontros científicos biblioteconômicos, considerados os principais eventos científicos em Biblioteconomia no país durante os anos 1980, com a ocasional participação de profissionais ligados aos países comunistas nesses eventos (SANTOS, HIDALGO, 2012).

Em 1970, surgia o curso de Informação técnico científica e biblioteconomia na Universidade de Havana, consolidando o surgimento do profissional em Ciência da informação e biblioteconomia no país (PÉREZ MATOS, 2005). A partir de 1974, cursos técnicos ligados a bibliotecas e a informação científica foram instituídos, apesar de terem mostrado um caráter irregular de funcionamento com o decorrer dos anos (PUERTAS; RODRIGUEZ, 2005a).

Nesses centros de ensino e pesquisa, a base teórica, tanto no campo em Ciência da informação quanto em biblioteconomia, ficaria diretamente ligada as correntes produzidas pela Informatika ${ }^{2}$ soviética, em especial o livro Fundamentos de La Informatica, escrito por A. I. Mikhailov, A. I. Chernyi, e R. S. Gilyarevskii, publicado originalmente em 1968 e traduzido para o espanhol em 1973, obra essa que se tornaria o principal guia para essas áreas no país até o início dos anos 1990 (PÉREZ MATOS, FERNANDEZ-MOLINA, 2010).

Em 1971, de forma a inserir o IDICT efetivamente no bloco comunista, foi assinado o convênio bilateral de informação IDICT-VINITI, que segundo Izquierdo (2004), possuiu três objetivos principais:

- Estabelecimento de estudo prévio das linhas mestras de colaboração no campo em informação científica, e apresentar propostas correspondentes aos órgãos superiores respectivos.

- Elaborar, com base no convênio geral entre as academias, planos de trabalho específico que respondam as condições de cada momento.

- Checar, mediante reuniões em Moscou e Havana, o estado do cumprimento das tarefas apresentadas nos planos de trabalho.

A partir desse convênio (e da supervisão de pesquisadores soviéticos como, por exemplo, R. S. Gilyarevskii), foi instituído, em 1973, o Sistema Nacional de Informação Científico e Técnica, que teve como principal objetivo coletar, processar e disseminar a informação científica e técnica produzida ou recebida em Cuba (GALÁN, 2009; IZQUIERDO, 2004).

\footnotetext{
${ }^{2}$ Denominação dada a Ciência da Informação na URSS a partir de 1966. 
Em novembro de 1975, na Reunião nacional de informação científico e técnicaconsiderada o principal evento do tipo no país nos anos 1970- foram discutidos e delineados a estrutura e funcionamento desse sistema, além de análise sobre os avanços iniciais do mesmo. Esse sistema sofreria ajustes entre 1981-83, com a coordenação de setores e organismos de pesquisa soviéticos (GALÁN, 2009).

Apesar da implantação de Planos Nacionais em Informação (PNI) a partir de 1967, que buscavam delimitar políticas sobre informação no país, somente em 1974, com a criação do Conselho Nacional em Informação Científica e Técnica, é que os PNI teriam seus projetos e propostas construídos a partir de objetivos macro, visando toda Cuba e diferentes setores econômicos do país (GALAN, 2009).

O primeiro projeto em grande escala referente à informação no país seria apresentado pelo PNI de 1977-82, onde foram desenvolvidos e implantados complexos multi setoriais de informação científica, consolidados a partir de leis que regiram seu funcionamento, e a criação de centros de informação em diferentes cidades cubanas, além da inserção do campo informacional do país em projetos internacionais, como, por exemplo, o UNISIST, promovido pela UNESCO, e em iniciativas ligadas ao bloco comunista. Esses complexos multi setoriais tinham como estrutura a diretoria geral, departamentos de serviços de informação, e departamentos de processos técnicos (IZQUIERDO, 2004; GALÁN,2009).

A partir desse programa fundava-se o INFOLAC, em 1982, que buscou diminuir o isolamento do campo informacional Cubano, estimulando projetos com países da América latina e Caribe (GALÁN, 2009).

No ano seguinte foram desenvolvidos os primeiros sistemas automatizados nos centros de informação e em algumas bibliotecas cubanas, sendo utilizados principalmente o modelo bielorrusso EC-1035 e o, em convênio norte-americano/soviético, ESTEL 4.2, com a criação dos primeiros bancos de dados em alguns centros, que seriam aprimorados durante a segunda metade dos anos 1980 (GALAN, 2009).

Consolidavam-se também a criação de organismos de grande porte que buscavam centralizar e organizar serviços de informação, sendo uma espécie de "intermédio" ente o IDICT e os diferentes polos industriais e econômicos de Cuba. Entre esses órgãos citam-se a Biblioteca Nacional de Ciência e Tecnologia (BNTC) e a Sociedade Cubana em Informação Científica, ambas instituídas em 1986 (PÉREZ MATOS, FERNANDEZ MOLINA, 2010).

Grande parte dos organismos em informação cubanos ficaram subordinados aos ditames do Plano de desenvolvimento acelerado da ciência e tecnologia (PACT), que ficou em vigor entre 1981-1990, onde os mesmos receberam considerável aporte financeiro para 
melhoria de sua estrutura, mas também recebendo críticas por apresentar metas e objetivos excessivamente uniformes, e não levando em consideração as diferenças e particularidades das bibliotecas e centros de pesquisa em determinadas regiões do país (GALÁN, 2009).

Cuba também mostraria diminuição no isolamento com outros campos em Ciência da Informação e biblioteconomia, conseguindo organizar e sediar encontros que uniram profissionais tanto do bloco capitalista quanto comunista, como no, por exemplo, 45은 encontro da Federação Internacional em Documentação, ocorrida em Havana em 1990 (IZQUIERDO, 2004).

\section{NOVOS E SOLITÁRIOS CAMINHOS: OS CAMPOS EM INFORMAÇÃO E BIBLIOTECAS DE CUBA APÓS O FIM DO BLOCO SOCIALISTA}

O sistema em informação científica e de bibliotecas em Cuba, no início dos anos 1990, apesar dos avanços e desenvolvimento, também apresentavam problemas e oposição.

Críticas sobre análises teóricas presas em demasia a visão soviética, excesso de centralização dos programas em informação cubanos, atrasos e deficiências desses centros em disponibilizar de forma rápida as informações pedidas pelos usuários, estrutura deficitária de várias bibliotecas e centros de informação, e a dependência financeira da URSS, que poderia por em risco a atualização dos computadores utilizados no país começaram, de forma tímida e localizada, a serem feitas por bibliotecários e profissionais da informação cubanos por quase toda a década de 1980. Porem, até o fim da ajuda comunista ao país, essas oposições foram rapidamente (e de forma severa) silenciadas pelo governo cubano (IZQUIERDO, 2004; GALÁN, 2009; VALDÉS, 2006).

Porém, entre 1989-91, o bloco comunista era (abruptamente) encerrado, com a dissolução do Comecon ${ }^{3}$ e da URSS em 1991. Em dois anos, Cuba perdia praticamente todos os seus laços políticos e econômicos existentes desde os anos 1960, entrando em uma instável fase, chamada por Fidel Castro de "Período especial em tempos de paz".

Os campos em Ciência da informação e biblioteconomia cubanas, nesse período, perceberiam que as críticas, mesmo que "isoladas", estavam corretas.

Tanto os centros de informação como as bibliotecas públicas cubanas tiveram que readaptar seus serviços automatizados de informação, tendo que, durante os anos 1990, substituir os modelos soviéticos utilizados (grande parte de baixo armazenamento e

\footnotetext{
${ }^{3}$ Conselho para Assistência Econômica Mútua, que visava à integração econômica dos países do bloco comunista, em atividade entre 1949 e 1991.
} 
obsoletos), por produzidos pelos EUA e Europa ocidental, o que se mostrou difícil, devido ao embargo econômico feito pelos Estados Unidos a Cuba desde 1960. Foram percebidos também a queda do número de livros e periódicos obtidos por esses organismos, em alguns casos chegando a sofrer cortes de 40\% em seu acervo (GALÁN, 2009).

Os EUA, como forma de desestabilizar o governo cubano, criou, durante grande parte dos anos 1990, algumas bibliotecas "clandestinas", com material ligado a autores ocidentais e publicações anti-Fidel Castro. Contudo, informações sobre o funcionamento, estrutura, quantas bibliotecas desse tipo ficaram em atividade e de que forma o governo de Fidel reprimiu esse tipo de organismo até o momento se mostram obscuras (GOTT, 2006).

A partir de 1992, projetos de inclusão de periódicos científicos cubanos em formato digital e eletrônico foram formulados e implantados pelo governo, sendo que na segunda metade dos anos 1990, algumas revistas científicas cubanas seriam inseridas em repositórios. Em 2004 foram implantados projetos como, por exemplo, a Biblioteca Virtual em Educação Superior (BIVES), buscando que os centros em informação e bibliotecas cubanas conseguissem manter seus sistemas informatizados atualizados e evitando a obsolescência dos computadores e sistemas utilizados, o que nem sempre obteve sucesso (GALÁN, 2009; SANTOS , HIDALGO, 2012).

Com o encerramento abrupto dos antigos laços de Cuba com o bloco socialista (incluindo o VINITI), os campos em Ciência da informação e biblioteconomia diminuiriam seu "isolamento" com o ocidente, mantendo o estímulo a realização de congressos e conferências internacionais. Nesse sentido, Havana sediou a 60 reunião da Federação Internacional das Associações e Instituições Bibliotecárias (IFLA), em 1994, e o 12을 Congresso Internacional de Informação, em 2012, ambos recebendo grande quantidade de cientistas da informação e bibliotecários das Américas (IZQUIERDO, 2004; SANTOS, HIDALGO, 2012).

Cuba "trocaria" a URSS e o leste europeu por Colômbia, Venezuela, México, Brasil e Espanha como os principais parceiros de trocas e aquisição de material bibliográfico e científico para suas bibliotecas e universidades. Apesar de o país sofrer um baque, em consequência do término do patrocínio advindo dos países comunistas, durante a primeira metade dos anos 2000, os campos em informação e biblioteconomia cubanos conseguiram, parcialmente, recuperar alguma produtividade de trabalhos publicados e de retorno de bibliotecas em atividade (SANTOS, PEREZ MATOS, FERNANDEZ MOLINA, 2011; GALAN, 2009).

A partir de 2000, com a consolidação de cursos em Cuba de mestrado e doutorado em Ciência da Informação e biblioteconomia, uma geração de mestres e doutores cubanos seriam formados no país, e não mais em pós-graduações oferecidas na antiga URSS ou Europa 
oriental. Os periódicos científicos cubanos em biblioteconomia e Ciência da Informação cubanos mantiveram-se em atividade, porém, a instável situação econômica em Cuba, fez com que boa parte delas ficassem indisponíveis em base de dados ou repositórios, e sendo publicados em caráter irregular (GALÁN, 2009).

Muitos pesquisadores dessas áreas publicariam seus trabalhos em revistas de outras disciplinas que conseguiram consolidar alguma regularidade ou mantêm seu material em repositórios, como, por exemplo, o ACIMED, em atividade desde 1993, ligado ao Centro de informação e comunicação em ciências médicas de Cuba.

Foi percebido também considerável número de trabalhos publicados por pesquisadores cubanos, após 2000, de caráter histórico, epistemológico e de cunho quantitativo, identificando como se deu o desenvolvimento do campo em Ciência da informação e biblioteconômico em Cuba, e quais as principais características dessas disciplinas científicas no país.

Novos Planos Nacionais de Informação foram implantados em 1999 e 2003, com o objetivo de adaptar Cuba a uma nova realidade sem o suporte dos antigos aliados comunistas, e também tentar identificar quais seriam as principais áreas de atuação nessa nova fase. Umas das principais medidas desses planos foram a reorganização dos complexos multi setoriais de informação científica, renomeados de Centros de informação e gestão tecnológicas, tentando criar vínculos empresariais com instituições privadas fora de Cuba e restringindo seu ramo de atuação para apenas as regiões aonde esses centros se localizam, diminuindo o funcionamento do antigo sistema de informação científica existente no país, sistema esse que sofreria cortes abruptos em sua estrutura durante os anos 1990 e 2000 (GALÁN, 2009).

Os PNI de 1999 e 2003, atualmente em atividade em Cuba, também apresentaram sugestões e propostas referentes a atividades ligadas ao acesso, desenvolvimento e disseminação da informação cubana, além da discussão sobre gerenciamento de recursos humanos e setoriais para os centros de informação e bibliotecas no país (GALÁN, 2009).

\section{CONSIDERAÇÕES FINAIS}

A presente pesquisa analisou o desenvolvimento da Ciência da Informação e biblioteconomia em Cuba durante o governo de Fidel Castro (1959-2008), identificando a evolução e principais características apresentadas por essas áreas no país.

Foi percebido que esses campos de pesquisa receberam estímulos e investimentos nos primeiros anos do regime de Castro, tanto em iniciativas do governo como pela atuação firme 
de bibliotecários cubanos. O surgimento do campo em informação do país e de órgãos como o IDICT, apesar de possuírem assistência de profissionais e organismos soviéticos, mantiveram certa autonomia no país por durante boa parte dos anos 1960.

Nos anos 1970, foram percebidos investimentos em grande porte, com a consolidação dos Planos Nacionais em Informação e do Sistema Nacional em Informação, que diferente de outros países da América do sul, ligados a uma realidade norte-americana e europeia, no âmbito cubano estavam diretamente vinculados aos ditames da URSS e do Comecon. Apesar de, em certa medida, a classificação dada por alguns autores dessa fase como o "período áureo" da Ciência da Informação no país se mostrar correta, essa realidade escondeu um campo excessivamente dependente do bloco socialista, além da pouca participação dos pesquisadores (e usuários) cubanos na formulação e ajustes desses centros e bibliotecas.

A partir dos anos 1990, essas disciplinas não somente tiveram que encarar essas questões, mas também lutaram para sobreviver a uma fase extremante instável e de recursos escassos, com a formulação de novos e bem mais modestos planos de informação, intentando, com dificuldade, recuperar a autonomia existente nesses campos durante os anos 1960. Mesmo com perdas e deficiências, os campos em Ciência da Informação e biblioteconomia de Cuba mantiveram-se em atividade, conseguindo diminuir seu isolamento com a Europa ocidental e America Latina, o que se mostrou vital para essas áreas, já que a fonte vinda do bloco comunista havia secado, e sem chance de retorno.

A presente pesquisa conclui que, apesar das limitações, a cena cubana em biblioteconomia e Ciência da informação possuiu consistência em sua estrutura e constituição e que, apesar das dificuldades sofridas por esses campos atualmente, ambas as disciplinas no país mantém-se como importante local de troca de dados entre profissionais da América Latina.

\section{Referências}

AYERBE, L. F. A Revolução Cubana. São Paulo: Editora UNESP, 2004.

FURIATI, C. Fidel Castro: uma biografia consentida. Rio de Janeiro: Revan, 2003.

GALÁN, I. F. Origen y desarrollo del sistema nacional de información en Cuba. ACIMED, v.19,n.6, p.1-35, 2009. Disponível em: http://scielo.sld.cu/pdf/aci/v19n6/aci03609.pdf (Acesso em 05/07/2013).

GOTT, R. Cuba: uma nova história. Rio de Janeiro: Jorge Zahar Editor, 2006. 
IZQUIERDO, E. P. Peculiaridades del desarrollo de las ciencias de la información en Cuba. ACIMED, v.12, n.1, 2004. Disponível em: http://scielo.sld.cu/pdf/aci/v12n1/aci06104.pdf (Acesso em 01/07/2013).

PERÉZ, L. G. ; HERRERA, A. C. Las bibliotecas en el contexto histórico colonial en Cuba . ACIMED ,v.14, n.6, 2006. Disponível em: http://scielo.sld.cu/scielo.php?pid=S102494352006000600015\&script=sci_arttext (Acesso em 02/07/2013)

PÉREZ MATOS, N. La formación bibliotecaria en Cuba: una mirada a través de los documentos. ACIMED , v.13, n.3, 2005. Disponível em: http://eprints.rclis.org/6676/1/aci09305.pdf (Acesso em 23/06/2013).

PÉREZ MATOS, N. La literatura bibliológica-informativa en Cuba. Parte I. Reflexión histórica. ACIMED, v. 15, n. $1 . \quad 2007$ a. Disponível em: http://eprints.rclis.org/8953/1/La_literatura_biblilogica-informativa_en_cuba.pdf (Acesso em 25/06/2013)

PÉREZ MATOS, N. La literatura bibliológico-informativa en Cuba. Parte II. Análisis de dominio del siglo XX. ACIMED, v. 15, n.3, 2007b. Disponível em: http://eprints.rclis.org/9500/1/La_literatura_bibliológico-

informativa_en_Cuba._Parte_II._Analisis_de_dominio_del_siglo_XX.pdf (acesso em 25/06/2013).

PÉREZ MATOS, N. ; FERNÁNDEZ MOLINA, J.C. History of library and information activities in Cuba: the relationship with its constitutional periods. Library and Information History, v.26, n.3, 2010, 213-224.

PUERTAS, Y. D. G.; RODRIGUEZ, M. C. B. Las bibliotecas públicas cubanas en el período 19591976. ACIMED, v.13, n.5, 2005 a. Disponível em: http://eprints.rclis.org/7255/1/aci05505.pdf (Acesso em 20/06/2013).

PUERTAS, Y. D. G.; RODRIGUEZ, M. C. B. Las bibliotecas públicas cubanas en la etapa prerrevolucionaria. ACIMED, v. 13, n.6. 2005b.

REIS FILHO, D. A. A revolução e o socialismo em Cuba: ditadura revolucionária e construção do consenso. In: Denise Rollemberg; Samantha Viz Quadrat. (Org.). A construção social dos regimes autoritários. Legitimidade, consenso e consentimento no século XX. Rio de Janeiro: Civilização Brasileira, 2011, vol. 2.

SANTOS, B. G. ; PÉREZ MATOS, N. ; FERNÁNDEZ MOLINA, J.C.. Servicios de información. Estudio terminológico de la producción profesional cubana en Bibliotecología y Ciencias de la Información: 1905-2008. Primera parte. Ciencias de la Información, v.42, n.2, 2011, 19-24.

SANTOS, C. O. G. ; HIDALGO, I. M. La biblioteca universitaria en Cuba, periodización de su desarrollo y tendencias actuales. ACIMED, v. 23, n.1, p.59-72, 2012. Disponível em: http://scielo.sld.cu/pdf/aci/v23n1/aci06112.pdf (Acesso em 26/06/2013).

SANTOS JUNIOR, R. L. ; PINHEIRO, L. V. R. . A infra-estrutura em informação científica e em ciência da informação na antiga União Soviética (1917-1991). Encontros Bibli, v. 15, p. 24-51, 2010.

SZULC, T. Fidel: Um Retrato Crítico. 2o edição. Rio de Janeiro: Editora Bestseller, 1987. 
VALDÉS, M. V. La biblioteca pública cubana en el período 1959-1989. ACIMED, v.14, n.1, 2006. Disponível

em: http://eprints.rclis.org/9135/1/http bvs.sld.cu_revistas_aci_vol14_1_06_aci05106.htm.pdf (Acesso em 26/06/2013)

VIVERO, N. V.; RIVERA, Z. ; COLUMBIÉ, R. L. ; RODRÍGUEZ, M. B. La revista Cuba Bibliotecológica: reflejo del desarrollo de la bibliotecología cubana en la década de los años 1950. ACIMED, v. 16, n.6, 2007. Disponível em: http://scielo.sld.cu/pdf/aci/v16n6/aci051207.pdf (Acesso em 01/07/2013). 